\title{
Clutch Size of a High-elevation Lizard, the Montane Toad-headed Agama (Phrynocephalus theobaldi Blyth 1863) from the Trans-Himalayas
}

\author{
Dimpi A. Patel ${ }^{1}$, Pankaj Raina ${ }^{1}$, Sunetro Ghoshal ${ }^{1}$, and Animesh Talukdar ${ }^{2}$ \\ ${ }^{1}$ Department of Wildlife Protection, Leh, Ladakh-194101, India (dmp8266@gmail.com) \\ ${ }^{2}$ Wildlife Institute of India, Chandrabani, Dehradun, Uttrakhand-248001, India
}

$\mathrm{O}$ the 40 species of toad-headed agamas in the genus Phrynocephalus that are distributed throughout the deserts of central Asia (Guo and Wang 2007), six viviparous species are restricted to high elevations. The Montane Toadheaded Agama (Phrynocephalus theobaldi; Fig. 1) is a small, diurnally active agama that occurs in the high deserts of India (Daniel 2002). Adult snout-vent lengths reach $54 \mathrm{~mm}$ and tail lengths $58 \mathrm{~mm}$. These largely insectivorous lizards have flattened bodies, projecting eyelids that protect the eyes from blowing sand, and nostrils that can be closed (Sharma 2002).

Little is known about reproduction in Phrynocephalus theobaldi. Jin and Brown (2013) stated that females give live birth to 1-4 young and Kästle et al. (2013) indicated that broods consisted of 1-2 neonates. Evaluating the reproductive status of a live-bearing lizard by means of palpation (e.g., Holmes 2004) is not always accurate, and dissection necessitates killing the lizard. Herein, we used radiography as a non- invasive technique to diagnose pregnancy in an adult female in Ladakh, India.

We captured two adult Phrynocephalus theobaldi during an ongoing study on 14 July 2019 near Phyang $\left(34.18911^{\circ} \mathrm{N}\right.$, $77.42433^{\circ} \mathrm{E}$ ), in the Leh District of Ladakh, India (Fig. 2). One female (Fig. 3) had a distended abdomen and was presumed to be pregnant. Using a 40 -inch focal film distance with a tabletop technique of $200 \mathrm{~mA}, 1 / 120 \mathrm{sec}$, and 56-64 $\mathrm{kVp}$, both lizards were radiographed using radiolucent tap restraints (e.g., Mader 2006), Kodak Lanex regular screens, Kodak X-Omaticcassetee, and Kodak TMG film (Eastman Kodak Company, Rochester, New York) developed in an automatic Kodak RPX-Omatic Processor.

Dorsal, ventral, and lateral radiographic projections revealed the presence of rounded opaque structures in the caudal abdomen arranged in a linear overlapping pattern (Fig. 4) and an embryo in the oviduct. We observed the lizards in

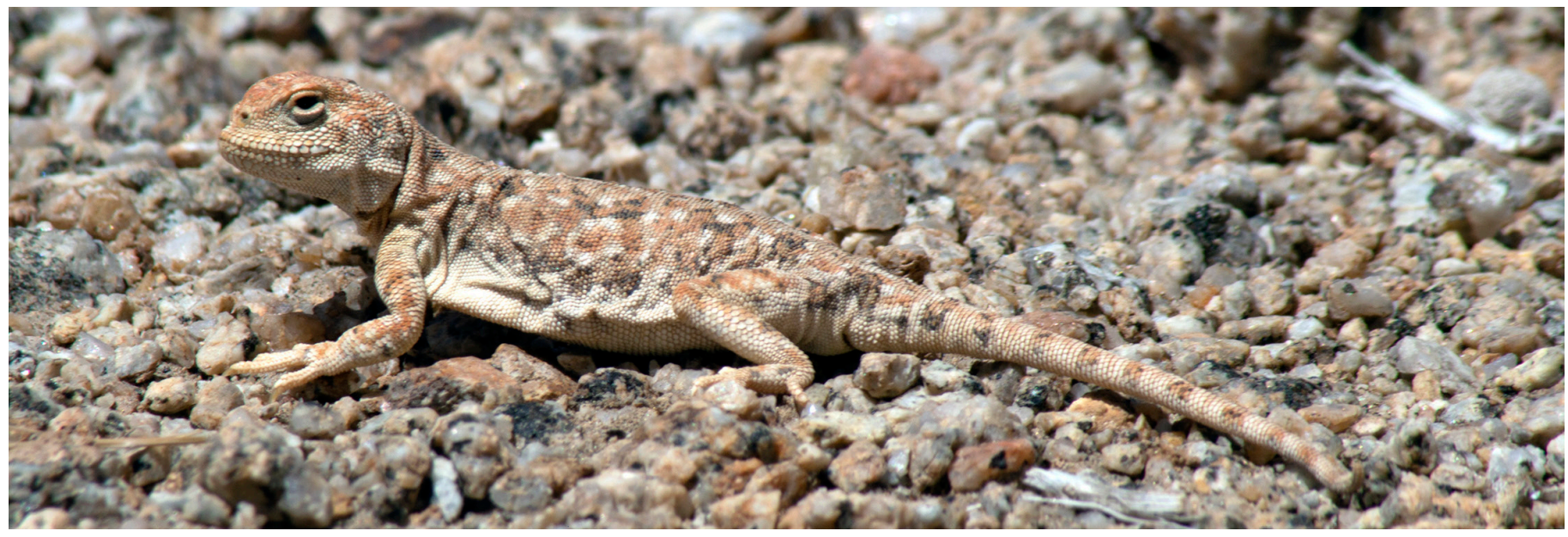

Fig. 1. An adult Montane Toad-headed Agama (Phrynocephalus theobaldi). Photograph by Akhilesh Tambe. 


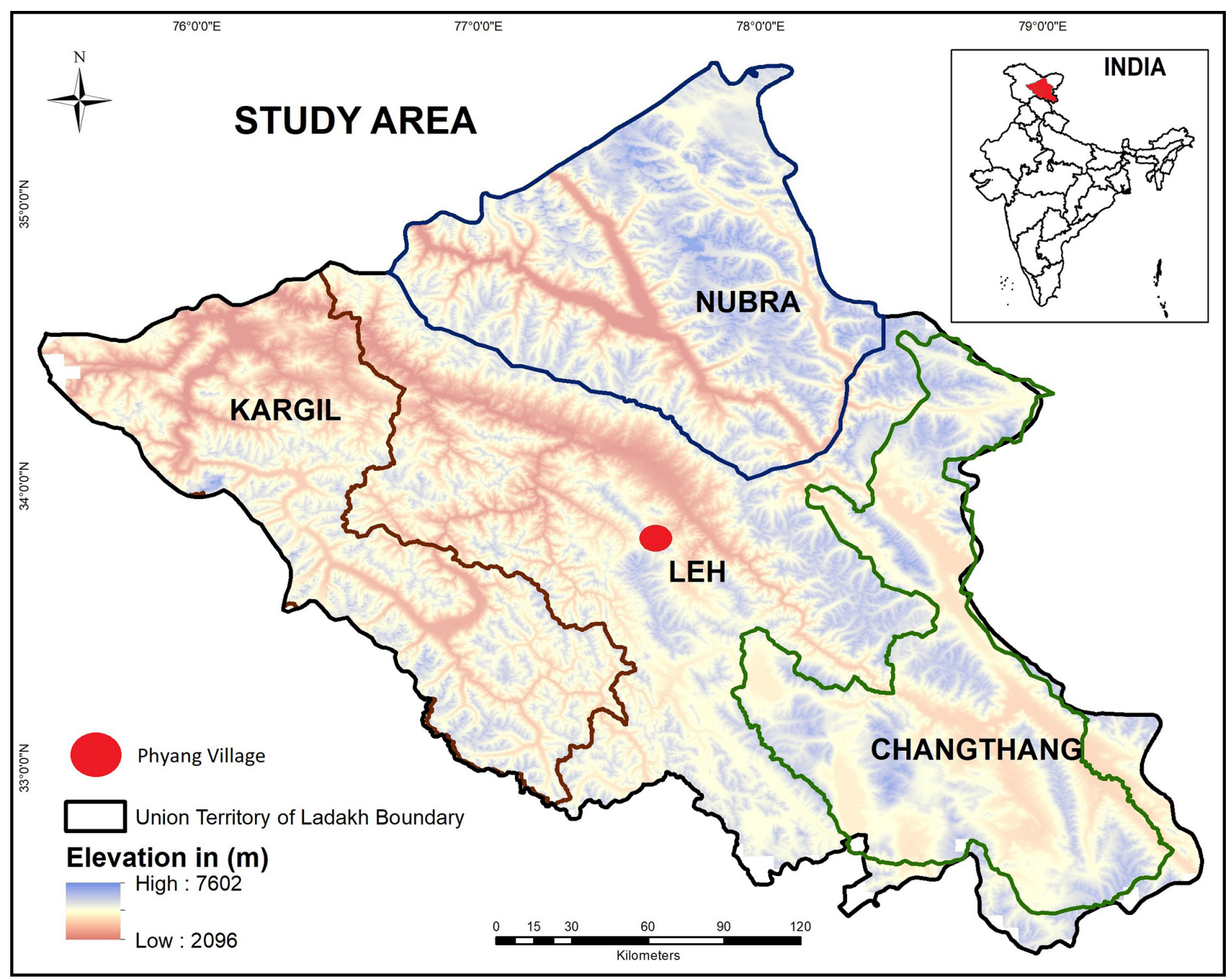

Fig. 2. Map showing the location of the study area near Phyang, Leh, Ladakh, India.

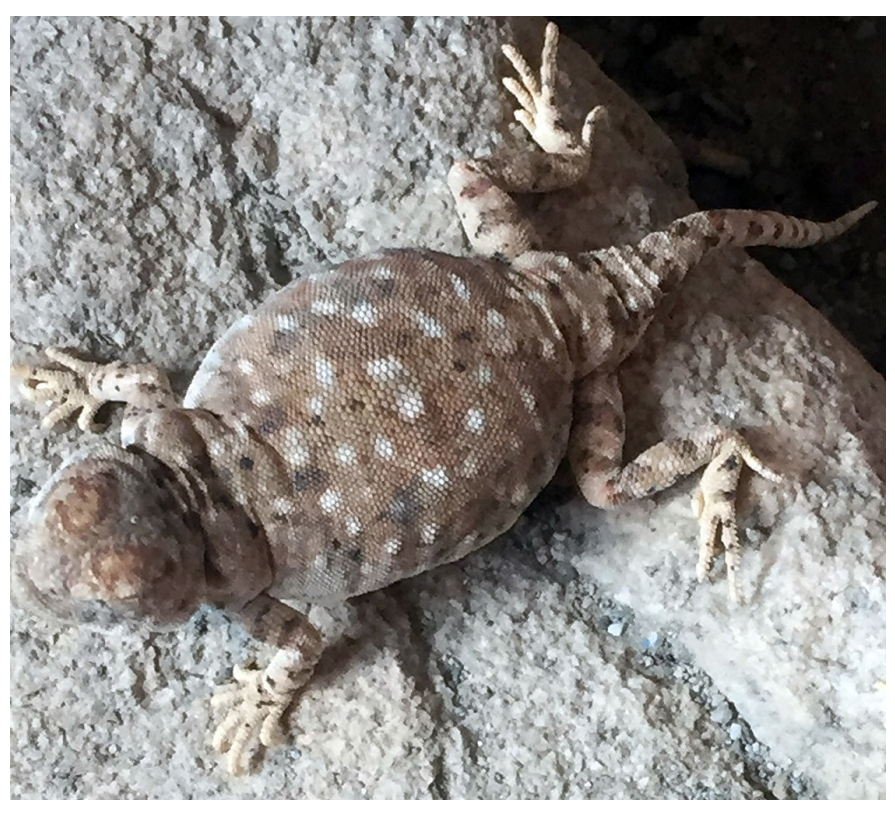

Fig. 3. Gravid female Montane Toad-headed Agama (Phrynocephalus theobaldi). Photograph by Dimpi. A. Patel. captivity for five days, during which the female gave birth to five young (Fig. 5). Average snout-vent and tail lengths of the neonates were $22.55 \mathrm{~mm}$ and $23.97 \mathrm{~mm}$, respectively. We did not determine sexes because of their small sizes. The brood size of five is the largest observed in $P$. theobaldi to date.

\section{Acknowledgments}

We thank the National Mission on Himalayan Studies and Department of Wildlife Protection, Ladakh (UT) for support and for granting permission to execute this work. We also extend our gratitude to Ms. Anchal Bhasin, Mr. Hussain Reshamwala, Mr. Akhilesh Tambe, Mhd. Akram, Mr. Varun Alagar, and Mr. Debaprasad Sengupta for their extensive support for the work and photographs. We also thank Ms. Padma for her help in the laboratory.

\section{Literature Cited}

Daniel, J.C. 2002. The Book of Indian Reptiles. Bombay Natural History Society, Mumbai, India. 

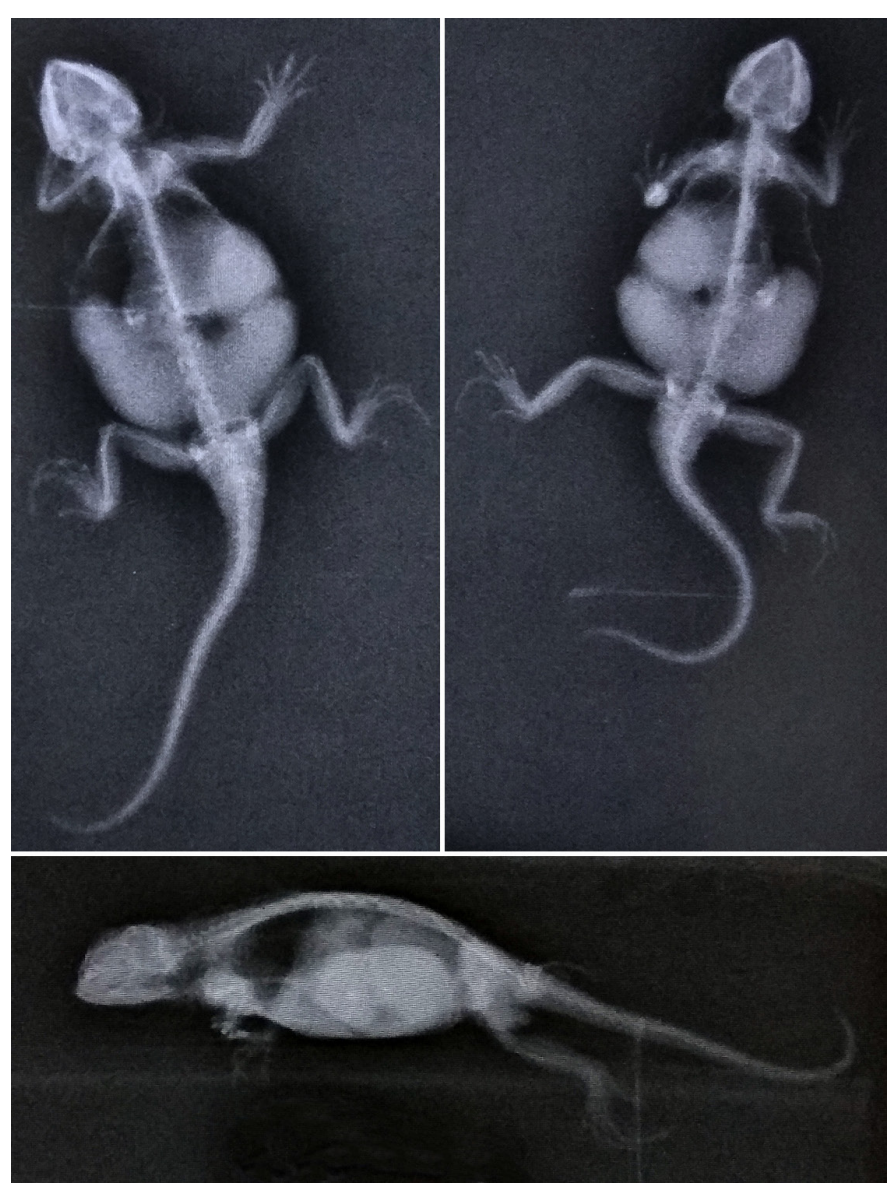

Fig. 4. Dorsal (top left), ventral (top right), and lateral (lower) radiographs of a gravid female Montane Toad-headed Agama (Phrynocephalus theobaldi). Courtesy of the National Mission on Himalayan Studies and the Department of Wildlife Protection, Leh, Ladakh, India.

Guo, X. and Y. Wang. 2007. Partitioned Bayesian analyses, dispersal-vicariance analysis, and the biogeography of Chinese toad-headed lizards (Agamidae: Phrynocephalus): A re-evaluation. Molecular Phylogenetics and Evolution 45: 643-662.

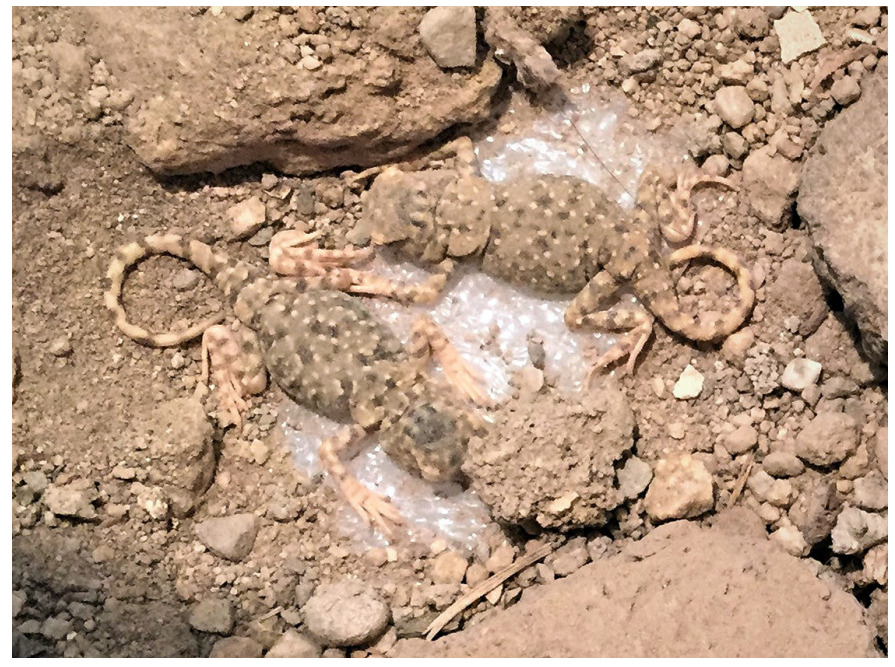

Fig. 5. Two of the five neonatal Montane Toad-headed Agamas (Phrynocephalus theobaldi). Photograph by Dimpi. A. Patel.

Holmes, K. 2004. The female reproductive cycle of a viviparous skink, Oligosoma maccanni, in a subalpine environment. Unpublished Ph.D. Dissertation, University of Otago, Dunedin, New Zealand.

Jin, Y.T. and R.P. Brown. 2013. Species history and divergence times of viviparous and oviparous Chinese toad-headed sand lizards (Phrynocephalus) on the Qinghai-Tibetan Plateau. Molecular Phylogenetics and Evolution 68: 259-268.

Kästle, W., K.R. Rai, and H.H. Schleich. 2013. Field Guide to Amphibians and Reptiles of Nepal. ARCO-Nepal e.V., München, Germany.

Mader, D.R. 2006. Reptile Medicine and Surgery. Second Edition. Saunders, St. Louis, Missouri.

Sharma, R.C. 2002. The Fauna of India and the Adjacent Countries. Reptilia. Volume II (Sauria). Zoological Survey of India, Kolkata, India.

Wapstra, E. and R. Swain. 2001. Geographic and annual variation in life-history traits in a temperate zone Australian skink. Journal of Herpetology 35: 194-203.

Wilson, J.L. and A. Cree. 2003. Extended gestation with late autumn births in a cool climate viviparous gecko from southern New Zealand (Reptilia: Naultinus gemmeus). Austral Ecology 28: 339-348. 